\title{
APLICAÇÃo DA ANÁLISE ENVOLTÓRIA DE DADOS PARA EFICIÊNCIA DA PRODUÇÃO DE ALFACE SOB CULTIVO PROTEGIDO
}

\author{
Jaqueline Bonfim de Carvalho ${ }^{1}$, Omar Jorge Sabbag ${ }^{2}$, Rayner Sversut Barbieri ${ }^{1}$
}

\footnotetext{
${ }^{1}$ Mestre em Agronomia pela Universidade Estadual Paulista, Câmpus de Ilha Solteira (SP).

${ }^{2}$ Docente do Departamento de Fitotecnia, Tecnologia de Alimentos e Socio economia (DFTASE), Universidade Estadual Paulista, Câmpus de Ilha Solteira (SP).
}

RESUMO: A produção de folhosas ocupa lugar de destaque no Brasil, porém possui limitações como altas temperaturas, excesso de chuvas ou secas, granizo e geadas, em que uma alternativa é o cultivo em ambiente protegido. Logo a importância de se avaliar a eficiência na produção de alface permite mapear produtos com menor consumo de recursos. Essa eficiência pode ser analisada por meio da técnica DEA (Data Envelopment Analysis). Metodologicamente, 10 produtores que mantinham as mesmas práticas foram entrevistados e avaliados por meio da análise DEA, com orientação input. Os inputs considerados foram: investimentos, mão de obra, irrigação e adubação, bem como dois outputs, referente à produção e receita bruta. Apenas uma unidade foi considerada eficiente, quando analisada a eficiência composta das unidades tomadoras de decisão (DMU) da amostra. Conclui-se que as DMU's devem se orientar para um melhor gerenciamento de suas propriedades, visando diminuir os recursos utilizados mantendo a produção constante.

Palavras-chave: Lactuca sativa L. Análise DEA. Desempenho. Gestão.

\section{APPLICATION OF DATA ENVELOPMENT ANALYSIS FOR LETTUCE PRODUCTION EFFICIENCY UNDER PROTECTED CULTIVATION}

\begin{abstract}
Production of greenery occupies a prominent place in Brazil, however it has limitations as high temperatures, excessive rain or drought, hail and frost in which an alternative is the cultivation of these crops in greenhouses. Soon the importance of evaluating the efficiency in the production of lettuce allows you to map products with lower resource consumption. This efficiency can be analyzed by technique DEA (Data Envelopment Analysis). Methodologically, 10 producers who held the same practices were interviewed and evaluated by DEA analysis, with guidance input. The inputs considered were: investment, labor, irrigation and fertilization as well as two outputs, relative on production and gross revenue. Only one unit was considered efficient, when analyzing the composed efficiency of decision makers units (DMU) of the sample. It concludes that the DMU's should move towards better management of its properties, aiming to reduce the resources used while maintaining constant production.
\end{abstract}

Key words: Lactuca sativa L. DEA analysis. Performance. Management.

Cultura Agronômica, Ilha Solteira, v.25, n.3, p.317-328, 2016 


\section{INTRODUÇÃO}

Sendo a hortaliça folhosa mais importante economicamente para o Brasil, a alface (Lactuca sativa L.) é cultivada em diversas regiões do país, graças à modernização da agricultura. Nunes (2007) refere-se à modernização por um processo de transformação chamado "Revolução Verde" na agricultura, que teve início a partir da segunda guerra mundial. Neste processo veio à utilização de máquinas, insumos e técnicas produtivas que permitiram aumentar a produtividade do trabalho e da terra.

A partir dessa época houve um avanço tecnológico, como a mecanização e tecnificação dos meios de produção, agregando novos padrões tecnológicos, como maneiras de complementar as famílias e agricultores no tocante à racionalidade produtiva. No que concerne a hortícolas, mais precisamente a alface, se teve larga adaptação a diferentes condições climáticas, possibilidade de cultivos sucessivos no mesmo ano, boa preferência e demanda dessa hortaliça, fazendo com que seja também a preferida entre os olericultores que a cultivam em condições de campo ou protegido (FERREIRA et al., 2009).

Difundido em diversas áreas de produção, o cultivo protegido tem boa aceitabilidade, graças à exploração racional de pequenas áreas, permitindo a obtenção de produções elevadas e de melhor qualidade, além do agricultor ter uma garantia de colheita (QUEIROZ et al., 2004). Entretanto, a cultura possui alguns entraves para seu cultivo; Silva (2009) cita que o comprometimento da produção da cultura da alface se deve a adversidades climáticas como altas temperaturas, fotoperíodo longo, verões chuvosos e temperaturas extremamente baixas. Uma forma de minimizar esses riscos é considerar a alternativa da utilização do cultivo em ambiente protegido.

O cultivo comercial de hortaliças em ambiente protegido é uma atividade solidificada e crescente, em que a capacidade de produção intensiva em pequenas áreas atende a grande demanda de centros urbanos, tanto em quantidade como em qualidade de produtos (ARAÚJO et al., 2010).

Desta forma, se tem a importância de analisar a eficiência na produção de alface, permitindo então se traçar uma quantidade menor quanto ao consumo de recursos/insumos para uma determinada quantidade de produtos, levando uma maior rentabilidade de quem produz, trabalhando essa de maneira eficiente.

Charnes et al. (1978) formularam a Data Envelopment Analysis - DEA (Análise envoltória de Dados), constituindo-se da geração envoltória dos planos de produção observados, pertencentes a uma fronteira de produção, que são eficientes tecnicamente e seus níveis de consumo e de produção são ótimos. A técnica DEA verifica se cada unidade opera de maneira adequada ou não, relativamente a um elenco específico de recursos utilizados e de resultados obtidos, em comparação com unidades consideradas similares por seus administradores.

Essa eficiência pode ser avaliada pela técnica DEA, consistindo em uma análise multivariada não paramétrica que avalia a produtividade (ou eficiência) de Unidades Tomadoras de Decisão (Decision Making Units - DMU's), com base nas melhores práticas Cultura Agronômica, Ilha Solteira, v.25, n.3, p.317-328, 2016 
adotadas pelas unidades. Através da comparação entre as DMU's, ela fornece dados quantitativos sobre possíveis direções para melhorar o desempenho das unidades ineficientes (GIACOMELLO; OLIVEIRA, 2014).

De acordo com Macedo e Macedo (2003), que complementam a definição do termo DMU, este é definido como uma organização, departamento, divisão, unidade administrativa ou até um item cuja eficiência está sendo analisada. Em uma avaliação DEA, o conjunto de unidades devem ter em comum a utilização das mesmas entradas e saídas, serem homogêneas e possuírem autonomia na tomada de decisões. No que se referem às variáveis, cada uma destas deve trabalhar na mesma unidade de medida para todas as DMU, mas pode estar em unidades diferentes das outras.

De outra forma, por meio da análise DEA, se avalia a eficiência relativa de unidades produtivas que desenvolvem o mesmo tipo de atividade e que se diferenciam somente pela quantidade de inputs (entradas) utilizados ou pela quantidade de outputs (saídas) gerados, tratando-se de um modelo importante para definir estratégias na produção agrícola (CARVALHO; SABBAG, 2015).

Desse modo, objetivou-se avaliar o desempenho de sistemas de produção de alface sobre cultivo protegido de Ilha Solteira/SP, com vistas a avaliar os produtores de acordo com valores de eficiência composta, com a metodologia DEA.

\section{MATERIAL E MÉTODOS}

Os dados utilizados nessa pesquisa foram provenientes de questionários diagnósticos, aplicados em março de 2014, junto a produtores de alface do município de Ilha Solteira/SP

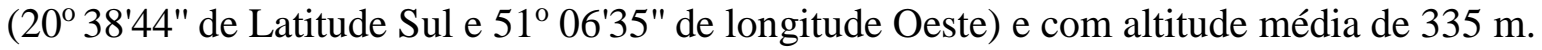

A amostra, de forma intencional, foi composta por 10 produtores que foram selecionados, possuindo como critério mínimo o cultivo protegido em canteiros com estufas ou sombrites, irrigação e mão de obra para todas as unidades.

Foram utilizadas seis variáveis neste trabalho, com quatro correspondendo aos insumos ou inputs $(\mathrm{X}=4)$, sendo: mão de obra empregada (horas ciclo'), irrigação (horas ciclo'), adubação (frequência ciclo') e investimentos $(\mathrm{R} \$)$, referentes aos principais gastos com a infraestrutura (tela sombrite, arcos, palanques de madeira, dentre outros) e conjunto de irrigação; e dois produtos ou outputs $(\mathrm{Y}=2)$, referentes à produção $\left(\right.$ maços ciclo $\left.^{-1}\right)$ e receita bruta $(\mathrm{R} \$$ ciclo-1 $)$.

Para justificar a quantidade de unidades analisadas, segundo Ali e Seiford (1993), é necessário que o número de unidades de produção seja, pelo menos, duas vezes o número de insumos $(\mathrm{X})$ e produtos $(\mathrm{Y})$, ou seja, $\geq 2(\mathrm{X}+\mathrm{Y})$, encaixando-se perfeitamente na definição de DMU's analisadas por DEA.

Para o desenvolvimento desse trabalho, foi atribuída a modelagem CCR, desenvolvido por Charnes et al. (1978), que trabalha com retornos constantes de escala, ou seja, qualquer

Cultura Agronômica, Ilha Solteira, v.25, n.3, p.317-328, 2016 
variação nas entradas (inputs) produz variação proporcional nas saídas (outputs), por meio da fórmula:

$$
\text { Min } h_{0} \text { sujeito à: } h_{0} x_{i o} \geq \sum_{k=1}^{n} x_{i k} \lambda_{i k} \forall i, y_{j 0} \leq \sum_{k=1}^{n} y_{j k} \lambda_{k}, \forall j, \text { e } \lambda_{k} \geq 0, \forall k \text {. }
$$

Em que: $h_{0}$ é a medida radial de eficiência técnica; $y_{i}$ é o valor do output i; $x_{j}$ é o valor do input j e $l_{k}$ é a importância da DMU k como referência para DMU 0 .

A orientação aplicada foi dada aos inputs, considerando a minimização da utilização dos principais fatores produtivos, dada a produção (output) obtida nas unidades produtoras de alface; de outra forma, desejou-se verificar se a produção atual justifica a quantidade de insumos empregados no ciclo produtivo.

Leta et al. (2005) propõem que a fronteira invertida permite a identificação de unidades produtivas consideradas "falsas eficientes", passando a indicar como mais eficientes (inversamente) as DMU's que gastaram mais insumos e geraram menos produtos. Com a obtenção da eficiência invertida, é possível se calcular a eficiência composta e composta normalizada. A eficiência composta descrita em Meza et al. (2005) é uma combinação da eficiência clássica (padrão) e da invertida, sendo obtida pela equação:

$$
\text { Eficiência composta }=\frac{\text { Eficiência Clássica }+(1-\text { Eficiência Invertida })}{2}
$$

Já a eficiência composta normalizada (composta*) é obtida dividindo o valor da eficiência composta pelo maior valor entre todos os valores de eficiência composta, como segue a equação:

\section{Eficiência composta* $=\frac{\text { Eficiência composta }}{\text { Máximo (eficiência composta) }}$}

Valores próximos a 1 significam que são mais eficientes. Representa assim um critério de "desempate" para as DMU's que sejam "benchmarking" na eficiência padrão, ou seja, unidades que sirvam de referências às práticas adotadas as unidades não eficientes.

Após a coleta de dados, estes foram submetidos ao auxílio do software SIAD - versão 3.0 (Sistema Integrado de Apoio à Decisão), apresentado por Meza et al. (2005).

\section{RESULTADOS E DISCUSSÃO}

Primeiramente uma estatística descritiva das variáveis de análise é apresentada na Tabela 1. O investimento médio total foi de $\mathrm{R} \$ 22.667,93$, com um desvio padrão de $\mathrm{R} \$ 13.391,42$, devido ao fato de diferentes materiais serem utilizados para as benfeitorias, como estufas/sombrite e para uso da irrigação, correspondendo aos custos de produção, inferindo que a amplitude de valores entre inputs-output justifica a variabilidade entre as DMU's. 
Tabela 1. Estatística descritiva das variáveis de unidades produtoras de alface sob cultivo protegido, Ilha Solteira/SP, 2014.

\begin{tabular}{|c|c|c|c|c|c|}
\hline Variáveis & Unidade & Média & Desvio Padrão & Mínimo & Máximo \\
\hline Investimentos (I1) & $\mathrm{R} \$$ & $22.667,93$ & $13.391,42$ & $2.840,50$ & $39.823,46$ \\
\hline Mão de obra (I2) & horas ciclo & 630 & 601 & 300 & 1.920 \\
\hline Irrigação (I3) & horas ciclo- & 34 & 52 & 15 & 160 \\
\hline Produção (O1) & maços ciclo- & 1.100 & 2561 & 300 & 7.000 \\
\hline Receita Bruta (O2) & $\mathrm{R} \$$ ciclo $^{-}$ & 2.750 & 6403 & 750 & 17.500 \\
\hline
\end{tabular}

O input investimento, consistindo dos gastos em reais com sistema de irrigação, cultivo protegido e benfeitorias no geral, fossem eles quaisquer tipos de materiais utilizados, foram considerados um fator de equidade para todas as unidades. Desta forma, todas as propriedades utilizadas nessa análise possuíam irrigação e cultivo protegido, ou seja, haviam realizado um investimento em sua unidade, porém com distintos materiais utilizados. Por exemplo, alguns produtores faziam uso de palanques de eucalipto que já se encontravam na propriedade, outros adquiriram em madeireiras. Ainda assim, alguns utilizam a tela de filme agrícola para a cobertura, outros de tela sombrite, influenciando os diferentes valores de mínimos e máximos observados na Tabela 1.

Neste sentido, ressalta-se que um dos princípios do método DEA é a comparabilidade entre as unidades com as mesmas condições tecnológicas - como ambiente protegido havendo apenas variações entre os inputs e outputs considerados.

Mesmo sendo alto o investimento da infraestrutura de um ambiente protegido, o retorno é valido, pois o produtor consegue aumentar sua produtividade e a qualidade do seu produto, além de conseguir ofertá-lo na entressafra. Bezerra Neto et al. (2005) analisaram a produtividade da alface sob diferentes tipos de telas e como testemunha a cultura sob campo aberto. Obtiveram diferenças significativas, observando ganhos de produtividade de até $25,45 \%$ quando utilizaram a tela, em relação à testemunha. Logo, o produtor que cultiva sob ambiente protegido poderá ter um melhor retorno econômico para sua unidade, justificando a utilização desse input no sistema de produção.

O desvio padrão para o input investimentos justificou-se pela magnitude correspondente à produção mínima e máxima de alface, com média de 1.100 maços por ciclo, com uma receita bruta média de $\mathrm{R} \$ 2.750,00$ por ciclo, comercializada em supermercados, cantinas, restaurantes e feiras da cidade. Vale destacar que o preço médio de venda no mercado regional foi de $\mathrm{R} \$ 2,50$ por cada maço.

O input mão de obra exibe uma variabilidade de 1.620 horas ciclo da cultura. Havia predomínio de produtores que utilizavam apenas a mão de obra da família, já outros utilizavam até quatro pessoas para o auxílio das atividades no canteiro. Porém, a média era de duas pessoas trabalhando com oito horas por dia, para um ciclo aproximado de 45 dias após o transplante da cultura no campo.

De acordo com Valle et al. (2011), a atividade familiar vai além do número de horas trabalhadas, pois é necessário que haja uma organização das atividades, para que não ocorra

Cultura Agronômica, Ilha Solteira, v.25, n.3, p.317-328, 2016 
ausência ou sobra de disponibilidade de trabalho durante os meses do ano; diferente da mão de obra terceirizada, que permanece conforme as leis trabalhistas vigentes. Entretanto, uma atividade de tempo integral e sem gerenciamento do sistema produtivo por parte do produtor pode estar predestinada a perder espaço para outras formas de ocupações.

Segundo Rezende et al. (2005), as operações manuais representam a maior proporção de custos operacionais, justificando-se a necessidade de se ter eficiência nesse insumo, para obter menor custo e maior produção.

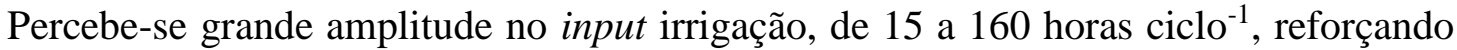
a variabilidade existente dentre as DMU's. Pires et al. (2008), cita que a necessidade de água se deve ao processo metabólico desempenhado pelas plantas, principalmente pelo processo de transpiração, e quando há a falta de água no solo ocorre o estresse hídrico. Portanto, uma elevada exigência de água para a cultura é essencial, e se não satisfeita pode afetar o seu crescimento e produção, justificando então o input irrigação ser um grande demandador de água.

A adubação foi utilizada somente uma única vez, no momento do pré-plantio, em todas as DMU's analisadas, não sendo uma variável constituinte para avaliar o grau de eficiência, pois todas as unidades obtiveram a mesma quantidade desse input.

Ao analisar os índices de eficiências das DMU's (Tabela 2), percebe-se que a DMU 1 e a DMU 3 foram as que apresentaram $100 \%$ de eficiência padrão, sendo benchmarking para as demais DMU's.

Tabela 2. Lista das 10 DMU's com índices de eficiências para unidades produtoras de alface sob cultivo protegido, Ilha Solteira/SP, 2014.

\begin{tabular}{|c|c|c|c|c|c|}
\hline \multirow{2}{*}{ DMU's } & \multicolumn{4}{|c|}{ Eficiências } & \multirow{2}{*}{ Ordem } \\
\hline & Padrão & Invertida & Composta & Composta normalizada & \\
\hline 1 & 1 & 0,29 & 0,85 & 0,99 & 2 \\
\hline 2 & 0,91 & 0,81 & 0,55 & 0,64 & 3 \\
\hline 3 & 1 & 0,29 & 0,86 & 1 & 1 \\
\hline 4 & 0,73 & 1 & 0,36 & 0,42 & 8 \\
\hline 5 & 0,65 & 0,8 & 0,42 & 0,49 & 6 \\
\hline 6 & 0,68 & 0,5 & 0,59 & 0,68 & 5 \\
\hline 7 & 0,74 & 0,39 & 0,67 & 0,78 & 4 \\
\hline 8 & 0,43 & 1 & 0,21 & 0,25 & 9 \\
\hline 9 & 0,5 & 0,7 & 0,4 & 0,47 & 7 \\
\hline 10 & 0,28 & 1 & 0,14 & 0,17 & 10 \\
\hline
\end{tabular}

Essas DMU's são unidades modelos a serem seguidas pelas demais, dado o mesmo conjunto de inputs e mesmas práticas adotadas. Nota-se que representa somente $20 \%$ da amostra, demonstrando que existe má alocação dos recursos por parte dos produtores, dado uma produção constante de hortaliças, seguindo a orientação adotada. $\mathrm{O}$ restante das unidades não está trabalhando de maneira eficiente, principalmente a DMU 10, que dentre o conjunto de dados, obteve apenas $28 \%$ de eficiência.

Cultura Agronômica, Ilha Solteira, v.25, n.3, p.317-328, 2016 
As unidades eficientes na eficiência padrão (1 e 3) obtiveram investimentos próximos e produção semelhantes, sendo 6.750 maços ciclo ${ }^{-1}$ referente a DMU 3 e 7.000 maços ciclo ${ }^{-1}$ para a DMU 1, valor máximo da produção na Tabela 1.

Entretanto, quando se analisa a eficiência composta normalizada, observa-se que apenas a DMU 3 obteve índice de 100\% de eficiência. Essa análise permite que haja um critério de desempate para as DMU's eficientes pela eficiência padrão, permitindo uma maior discriminação dos resultados inicialmente considerados eficientes, fornecendo aos gestores destas unidades a priorização das ações a serem tomadas, uma vez evidenciadas as eficiências de cada uma das unidades sob a forma de um ranking (SOLIMAN et al., 2014), conforme expõe a Figura 1, destacando a posição relativa das DMU's para a relação input/output.

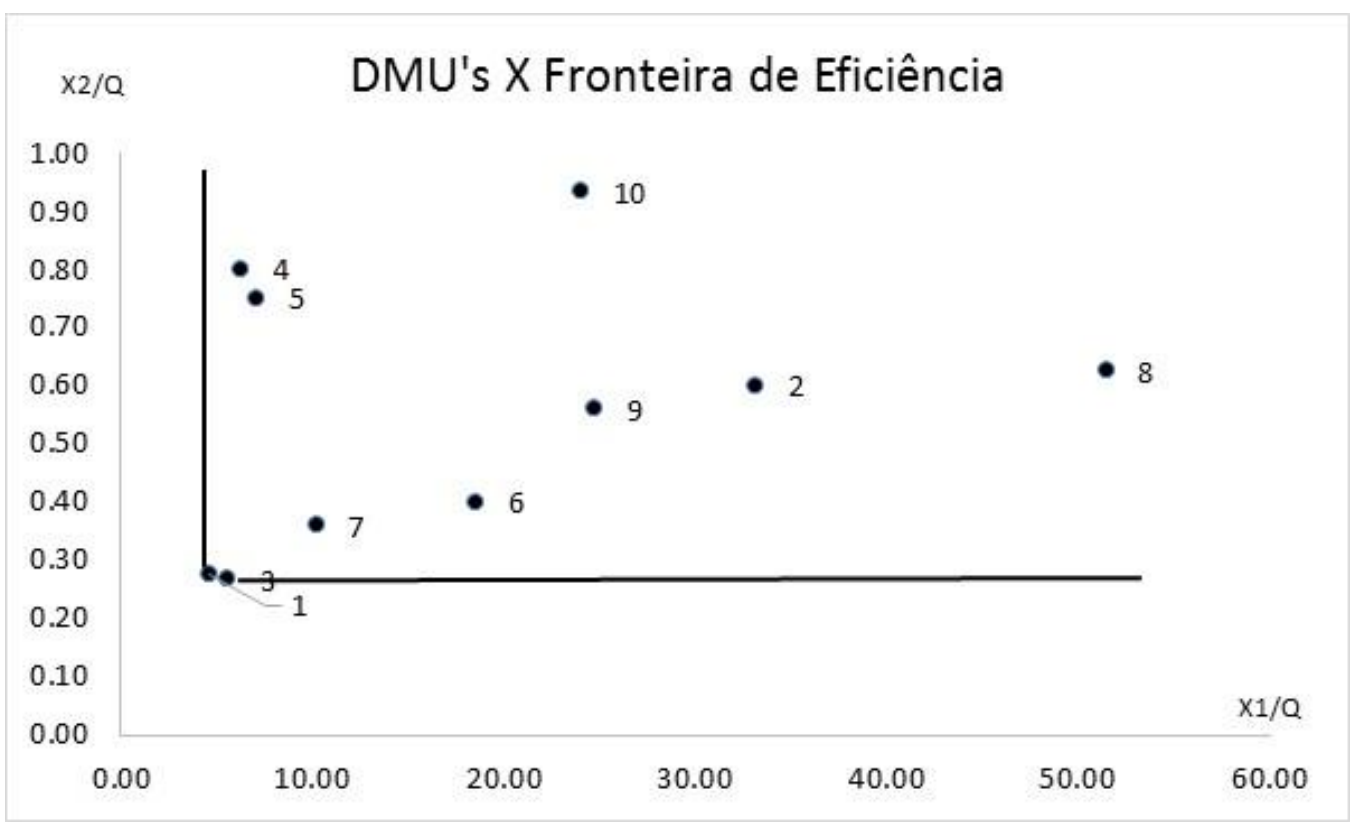

Figura 1. Fronteira eficiente no modelo CCR-I com uso dos inputs 1 e 2.

Desta forma, por exemplo, utilizando-se as variáveis input 1 (investimentos) e input 2 (mão de obra), relacionados à produção de alface (output 1), obtém-se a fronteira de eficiência DEA, utilizando o montante de investimentos (em R\$) e o $\mathrm{n}^{\mathbf{o}}$ de horas de trabalho (horas ciclo') divididos pela produção (maços ciclo-1 $^{-1}$ ), respectivamente para os eixos X e Y. Assim, a fronteira é formada então pelas unidades mais próximas dos eixos $\mathrm{X}$ e $\mathrm{Y}$. Neste caso, observa-se que apenas as unidades 1 e 3 fazem parte da fronteira eficiente e que os pontos mais distantes do eixo do gráfico indicam as unidades menos eficientes, correspondendo às DMU's 8 e 10 respectivamente.

Foi observado que o produtor o qual gerenciava a DMU 3 mantinha um turno de rega maior do que o produtor responsável pela DMU 1, com cerca de 55 horas ciclo $^{-1}$ a mais do que a unidade 1. Este fato reforça o encontrado por Bandeira et al. (2011), que analisando o manejo da irrigação para cultivo de alface em ambiente protegido, obteve resultados relativos à eficiência do uso de água, revelando uma resposta linear decrescente com o aumento dos níveis de irrigação, ou seja, a cultura responde melhor à aplicação de pequenas lâminas de irrigação, porém com alta frequência.

Cultura Agronômica, Ilha Solteira, v.25, n.3, p.317-328, 2016 
Outro fato observado foi de que a DMU 3 possui menor número de horas ciclo ${ }^{-1}$ para a componente mão de obra, com aproximadamente 1.800 horas. Já a DMU 1 possui 1.920 horas ciclo $^{-1}$. Pode-se dizer que esse insumo é um dos principais itens do ciclo produtivo de culturas agrícolas. As atividades exercidas são cotidianas, em que o número de horas deve ser otimizado, envolvendo a maioria das vezes a mão de obra familiar para as atividades de preparo da terra, plantio, colheita, controle de pragas, dentre outras atividades (ABH, 2013). Portanto, as unidades não eficientes podem seguir as práticas adotadas pela DMU 3.

Outro fator externo, diferente das quantidades de insumos e produtos de cada unidade avaliadas pelo método DEA, foi a presença do inseto "tripes" em suas unidades, que transmite o vírus da doença do vira-cabeça e que supostamente poderá interferir na produtividade da cultura. Em geral, o aumento populacional dessa praga está relacionado com altas temperaturas e clima seco, sendo sua maior incidência no período de novembro a março, nas principais regiões produtoras de alfaces dos estados de São Paulo e Minas Gerais. Os sintomas observados são a paralisação do crescimento e ausência da formação do miolo da alface. Em plantas jovens, os sintomas surgem nas folhas como um mosaico esbranquiçado; já em plantas mais velhas, ocorrem manchas necróticas e murcha marginal (COLARICCIO, 2015).

De forma geral, avaliações de produtividade e eficiência são muito focadas apenas na produtividade como indicador, e, segundo Gomes et al. (2003), podem ser equivocados, por não considerarem outros recursos para a medida de eficiência, como mão de obra e investimentos.

Neste sentido, Tupy e Yamaguchi (2002) inferem que o emprego de modelos DEA em agricultura pode apoiar as decisões de quem produz, ao indicar as fontes de ineficiência e as unidades que podem servir de referência às práticas adotadas (benchmarks).

Entretanto, para que as DMU's ineficientes alcancem patamares próximos a eficiência relativa quanto à tecnologia adotada, é necessário que tenha atenção principalmente aos fatores que se referem ao planejamento da mão de obra e irrigação nas unidades produtivas, bem como os insumos, os quais fizeram que fosse critério de desempate entre as unidades $100 \%$ produtivas do modelo adotado no presente trabalho.

Assim, percebe-se que a produção de hortaliças necessita de um planejamento, aliado a aplicação de estratégias na condução do cultivo, para que não ocorram perdas de produção, em que a análise de eficiência por meio da técnica DEA permite mostrar os gargalos de produção no qual o produtor se deve atentar, trabalhando com a otimização de seus fatores de produção. Neste sentido, o critério de eficiência na produção está associado aos conceitos de racionalidade econômica e de produtividade material e revela a capacidade da organização de produzir um máximo de resultados com um mínimo de recursos (BELLONI, 2000). 


\section{CONCLUSÃO}

No geral, as DMU's devem se orientar para um melhor gerenciamento de suas propriedades, visando diminuir os recursos utilizados como mão de obra, irrigação e gastos com investimentos, pois apenas $10 \%$ da amostra atingem $100 \%$ de eficiência composta normalizada, ou seja, a unidade consegue trabalhar em níveis ótimos.

A análise DEA permite auxiliar a gestão da agricultura familiar, definição de estratégias e as tomadas de decisão por parte dos agricultores buscando sempre a sustentabilidade em suas unidades agropecuárias, ou seja, utilizar somente quantidades adequadas de insumos para suas propriedades, trabalhando de maneira eficiente, evitando o desperdício, consequentemente obtenção de melhores resultados no que concerne ao rendimento produtivo das unidades.

\section{AGRADECIMENTOS}

À Fundação de Amparo à Pesquisa do Estado de São Paulo (FAPESP) pelo financiamento da pesquisa.

\section{REFERÊNCIAS BIBLIOGRÁFICAS}

ALI, A. I., SEIFORD, L. M. The Mathematical Programming Approach to Efficiency Analysis. In: FRIED, H. O., LOVELL, C. A. K., SCHIMIDT, S. S. (Orgs.). The Measurement of Productive Efficiency: Techniques and Application. New York: Oxford University Press. 1993. cap. 3, p. 120-159.

ALVES, J.; FIGUEIREDO, A. M. R.; ZAVALA, A. A. Z. Análise de eficiência em assentamentos rurais no Estado de Mato Grosso. Revista de Estudos Sociais, Cuiabá, v. 1, n. 21 , p.75-97, 2009.

ARAÚJO, T. S.; FIDELES FILHO, J.; KUMAR, K. K.; RAO, T. V. R. Crescimento da alface americana em função dos ambientes, épocas e graus-dias. Revista Brasileira Ciências Agrária, Recife, v. 5, n. 4, p.441-449, 2010.

ASSOCIAÇÃO BRASILEIRA DE HORTICULTURA - ABH. A participação da agricultura familiar na produção de hortaliças e o mercado dos orgânicos. Disponível em: http://www.abhorticultura.com.br/biblioteca/Default.asp?id=7751 . Acesso em: 26 set. 2013.

BANDEIRA, G. R. L.; PINTO, H. C. S.; MAGAlHÃES, P. S.; ARAGÃO, C. A.; QUEIROZ, S. O. P.; SOUZA, E. R.; SEIDO, S. L. Manejo de irrigação para cultivo de alface em ambiente protegido. Horticultura Brasileira, Vitória da Conquista, v. 29, n. 2, p.237-241, 2011.

BELLONI, J. A. Uma metodologia de avaliação da eficiência produtiva de Universidades Federais Brasileiras. 2000, 246 f. Tese (Doutorado em Engenharia de Produção) -Universidade Federal de Santa Catarina, Florianópolis, 2000.

Cultura Agronômica, Ilha Solteira, v.25, n.3, p.317-328, 2016 
BEZERRA NETO, F.; ROCHA, R. C. C.; NEGREIROS, M. Z.; ROCHA, R. H.; QUEIROGA, R. C. F. Produtividade de alface em função de condições de sombreamento e temperatura e luminosidade elevadas. Horticultura Brasileira, Vitória da Conquista, v. 23, n. 2, p.189-192, 2005.

CARVAlHO, J. B.; SABBAG, O. J . Análise de eficiência da produção de alface no noroeste de São Paulo. Revista Agroambiente online, Boa Vista, v. 9, n. 2, p.152-160, 2015.

CHARNES, A.; COOPER, W. W.; RHODES, E. Measuring the efficiency of decision making units. European Journal of Operational Research, Amsterdam, v. 2, n. 6, p.429444, 1978.

COLARICCIO, A. Vira-cabeça pode causar prejuízos de $100 \%$ à alface. Revista campos e negócios. 2015. Disponível em http://www.revistacampoenegocios.com.br/vira-cabecapodem-causar-prejuizos-de100-a-alface-2/ : Acesso em: 15 out 2015.

FERREIRA, R. L. F.; ARAÚJO NETO S. E.; SILVA S. S.; ABUD E. A.; REZENDE M. I. F. L.; KUSDRA J. F. Combinações entre cultivares, ambientes, preparo e cobertura do solo em características agronômicas de alface. Horticultura Brasileira, Vitória da Conquista, v. 27, n. 3, p.383-388, 2009.

GIACOMELlO, C. P.; OLIVEIRA, R. L. Análise envoltória de dados (DEA): Uma proposta para avaliação de desempenho de unidades acadêmicas de uma universidade. Revista GUAL, Florianópolis, v. 7, n. 2, p.130-151, 2014.

GOMES, E. G.; MELlo, J. C. C. B. S.; BIONDI, L. N. Avaliação de Eficiência por Análise de Envoltória de Dados: conceitos, aplicações à agricultura e integração com sistemas de informação geográfica. Campinas: Embrapa Monitoramento por Satélite, 2003. 39 p. (Embrapa Monitoramento por Satélite. Documentos, 28).

LETA, F. R.; MELLO, J. C. C. B. S.; GOMES, E. G.; MEZA, L. A. Métodos de melhora de ordenação em DEA aplicados à avaliação estática de tornos mecânicos. Investigação Operacional, Lisboa, v. 25, n. 2, p.229-242, 2005.

MACEDO, M. A. S; MACEDO, H. D. R. Avaliação de performance financeira através da análise envoltória de dados: um estudo de caso em unidades de negócio. In: CLADEA, 38., 2003, Lima. Anais.... Lima: CLADEA, 2003. 1 CD-ROM.

MEZA, L. A.; BIONDI NETO, L.; MELlO, J. C. C. B. S.; GOMES, E. G. ISYDS Integrated System for Decision Support (SIAD - Sistema Integrado de Apoio à Decisão): a software package for data envelopment analysis model. Pesquisa Operacional, Rio de Janeiro, v. 25, n. 3, p.493- 503, 2005.

NUNES, S. P. O desenvolvimento da agricultura brasileira e mundial e a idéia de Desenvolvimento Rural. Conjuntura Agrícola. Boletim Eletrônico Deser, Curitiba, n. 157, p.05-17, 2007.

Cultura Agronômica, Ilha Solteira, v.25, n.3, p.317-328, 2016 
PIRES, R. C. M.; ARRUDA, F. B.; SAKAI, E.; CALHEIROS, R. O.; BRUNINI, O. Agricultura Irrigada. Revista Tecnologia \& Inovação Agropecuária, São Paulo, v. 1, n. 1, p.98-111, 2008.

QUEIROZ, S. O. P.; TESTEZLAF, R.; MATSURA, E. E. Avaliação de equipamentos para a determinação da condutividade elétrica do solo. Irriga, Botucatu, v. 10, p.279-287, 2004.

REZENDE, B. L. A.; CECÍlio FIlHO, A. B.; CATElAN, F.; MARTINS, M. I. E. G. Análise econômica de cultivos consorciados de alface americana x rabanete: um estudo de caso. Horticultura Brasileira, Vitória da Conquista, v. 23, n. 3, p.853-858, 2005.

SILVA, E. C. Anita: cultivar de alface de verão para cultivo protegido no solo e em hidroponia. Horticultura Brasileira, Vitória da Conquista, v.27, n. 2, p.260-262, 2009.

SOLIMAN, M.; SILUK, J. C. M.; NEUENFELDT, J. R. A. L.; CASADO, F. L.; PARIS, S. R. Modelagem para avaliação da eficiência técnica de unidades universitárias. GEPROS. Gestão da Produção, Operações e Sistemas, Bauru, Ano 9, n. 1, p.69-83, 2014.

TUPY, O.; YAMAGUCHI, L. C. T. Identificando benchmarks na produção de leite. Revista de Economia e Sociologia Rural, Brasília, v. 40, n. 1, p.81-96, 2002.

VALLE, C. D.; FRITZEN, L.; HILLESHEIN, L. P. Agricultura familiar: relação entre disponibilidade e necessidade do fator trabalho na região do médio alto Uruguai. Synergismus scyentifica, Pato Branco, v. 06, n. 1. p.01-09, 2011. 
